\title{
Ocular Pharmacology
}

The Journal of Clinical Pharmacology 2016, 56(5) 517-527

(c) 2015, The American College of

Clinical Pharmacology

DOI: 10.1002/jcph.634

\section{Gary D. Novack, $P h D^{1,2}$ and Alan L. Robin, $M^{3,4,5}$}

\begin{abstract}
Ophthalmic diseases include both those analogous to systemic diseases (eg, inflammation, infection, neuronal degeneration) and not analogous (eg, cataract, myopia). Many anterior segment diseases are treated pharmacologically through eye drops, which have an implied therapeutic index of local therapy. Unlike oral dosage forms administered for systemic diseases, eyedrops require patients not only to adhere to treatment, but to be able to accurately perform-ie, instill drops correctly.

Anatomical and physiological barriers make topical delivery to the anterior chamber challenging-in some cases more challenging than absorption through the skin, nasal passages, or gut. Treatment of the posterior segment (eg, vitreous, retina, choroid, and optic nerve) is more challenging due to additional barriers. Recently, intravitreal injections have become a standard of care with biologics for the treatment of macular degeneration and other diseases. Although the eye has esterases, hydroxylases, and transporters, it has relatively little CYP450 enzymes. Because it is challenging to obtain drug concentrations at the target site, ocular clinical pharmacokinetics, and thus pharmacokinetic-pharmacodynamic interactions, are rarely available. Ophthalmic pharmaceuticals require consideration of solubility, physiological $\mathrm{pH}$, and osmolarity, as well as sterility and stability, which in turn requires optimal pharmaceutics. Although applied locally, ocular medications may be absorbed systemically, which results in morbidity and mortality (eg, systemic hypotension, bronchospasm, and bradycardia).
\end{abstract}

\section{Keywords}

ophthalmology, pharmacology, glaucoma, macular degeneration

The human eye has several embryological origins: the lens is derived from ectoderm, the retina and optic nerve derive from the forebrain, and the accessory structures derive from the mesenchyme. ${ }^{1}$ The uniqueness of the eye as a sensory organ providing us with the richness of vision is known to all. However, also unique is that the eye is a homunculus with cardiovascular, neuronal, and other systems. Although relatively small, the eye is an extremely complex organ and unique in many ways. The size and dimensions of the eye are important, as a larger eye, as in myopia or congenital glaucoma, can decrease visual function and put the patient at risk of other conditions (eg, blindness or retinal detachments). The media between the world around it and the retina (analogous to film or sensors in a camera) must be clear to allow for a distortion-free image. In their normal states, the cornea and lens therefore have no blood vessels and are reliant on the air and fluids around them for their nutrients. The fluid between the cornea and lens as well as the lens and the retina must be clear. The blood supply to the eye is complex: it is supplied by both the ophthalmic artery and choroidal plexus. The choroid in particular is one of the most highly vascular regions in the body in terms of blood flow per mass. The regulation of flow within the ophthalmic artery is complex, as it depends not only on the pressure head of the systemic circulation but also on the intraocular pressure (IOP), which can constrict the blood vessels and impede flow. The retina has redundant systems to allow for high-resolution vision, both day and night, and color vision. As in other vertebrates, the majority of the human retina is involved with lower-resolution black-and-white peripheral vision, while only a small pinpoint is actively involved with central tasks such as reading. A schematic of the human eye is shown in Figure 1. A list of some of the most common ophthalmic pharmaceuticals is provided in Table 1.

Shown in Table 2 are the names for eye care specialists in the United States and their role in the health care system.

The eye is the only organ system where one can noninvasively directly observe a nerve and blood vessels. Often, ocular pathology is similar to that seen in systemic

\footnotetext{
'PharmaLogic Development, Inc., San Rafael, CA, USA

${ }^{2}$ Departments of Pharmacology and Ophthalmology, University of California, Davis, CA, USA

${ }^{3}$ Department of Ophthalmology, University of Maryland, Baltimore, MD, USA

${ }^{4}$ Department of Ophthalmology, University of Michigan, Ann Arbor, MI, USA

${ }^{5}$ Department of Ophthalmology, Johns Hopkins University, Baltimore, MD, USA
}

Submitted for publication 30 June 20I5; accepted 8 September 2015.

Corresponding Author:

Gary D. Novack, PhD, PharmaLogic Development, Inc., 17 Bridgegate Drive, San Rafael, CA 94903

Email: gary_novack@pharmalogic.com 


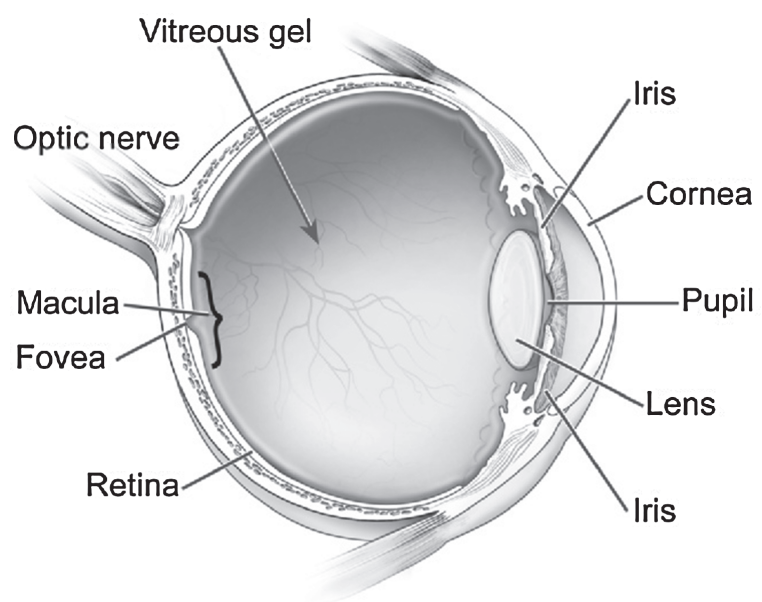

Figure I. Anatomy of human eye.

Table I. List of Marketed Ophthalmic Pharmaceuticals (US, Topical, Unless Specified Otherwise)

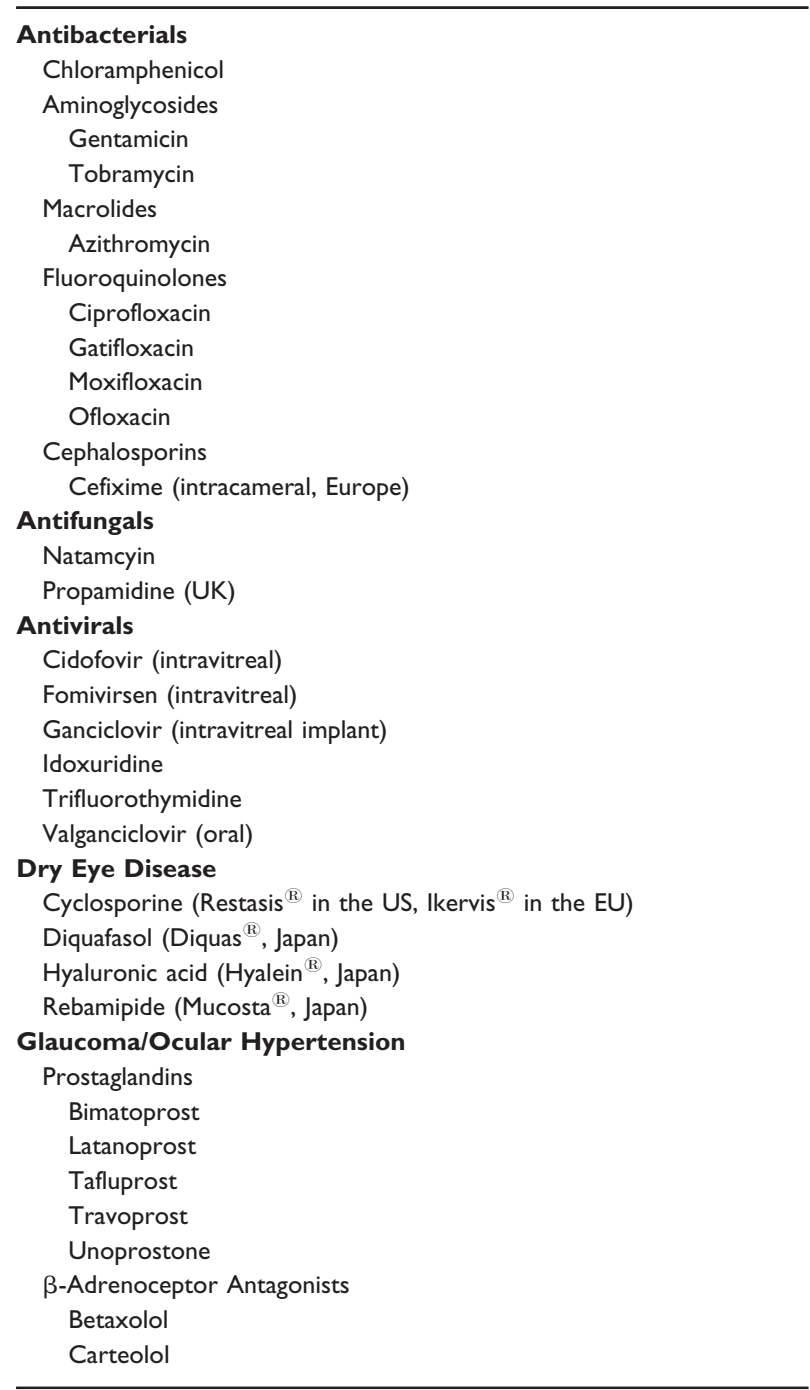

Table I. Continued

Levobunolol

Metoprolol

Timolol (maleate and hemihydrate salts)

Adrenergic Agonists

Apraclonidine

Brimonidine

Dipivefrin

Epinephrine

Carbonic Anhydrase Inhibitors

Brinzolamide

Dorzolamide

Antifibrotic Agent (During Surgery)

Mitomycin

Inflammation

Corticosteroids

Dexamethasone (topical, intravitreal, Ozurdex ${ }^{\circledR}$ )

Fluocinolone acetonide (Retisert ${ }^{\mathbb{R}}$, lleuvin ${ }^{\mathbb{R}}$ )

Fluorometholone

Prednisolone acetate

Triamcinolone acetonide $\left(\right.$ Triescence $^{\mathbb{R}}$, Trivaris $^{\mathbb{R}}$ )

Nonsteroidal Anti-Inflammatory Agents

Bromfenac

Diclofenac

Flurbiprofen

Ketorolac

Nepafenac

Allergy

Antihistamines

Alcaftadine

Azelastine

Bepotastine

Epinastine

Ketotifen

Olopatadine (Patanol ${ }^{\mathbb{R}}$, Pataday ${ }^{\mathbb{R}}$, Pazeo ${ }^{\mathbb{R}}$-various formulations)

Pheniramine

Mast cell stabilizer

Amlexanox

Cromoglycate

Surgery

Antimuscarinics

Atropine

Tropicamide

Cyclopentolate

Sympathomimetics

Phenylephrine

Cholinergic agonists

Acetylcholine

Carbachol

Ketorolac/phenylephrine

Retina-Choroidal Neovascularization due to Macular

Degeneration

Verteporfin (IV)

VEGF inhibitors*

Aflibercept (intravitreal)

Pegaptanib (intravitreal)

Ranizibumab (intravitreal)

Strabismus and Blepharospasm

Botulinum toxin (OnabotulinumtoxinA)

There are also fixed-dose combinations. These include corticosteroidantibiotics and ocular hypotensive medications.

* Some of the VEGF inhibitors are also approved for the treatment of diabetic macular edema and diabetic retinopathy due to diabetic macular edema. 
Table 2. Providers in Eye Care

\begin{tabular}{|c|c|c|c|c|c|c|c|c|}
\hline \multirow[b]{2}{*}{ Type of Provider } & \multicolumn{4}{|c|}{ Education (Minimum) } & \multicolumn{4}{|c|}{ Functions } \\
\hline & $\begin{array}{l}\text { Bachelor's } \\
\text { Degree }\end{array}$ & $\begin{array}{l}\text { Optometry } \\
\text { School }\end{array}$ & $\begin{array}{l}\text { Medical or } \\
\text { Osteopathic } \\
\text { School }\end{array}$ & Residency & $\begin{array}{l}\text { Prescribe } \\
\text { Spectacles }\end{array}$ & $\begin{array}{l}\text { Dispense } \\
\text { Spectacles }\end{array}$ & $\begin{array}{l}\text { Prescribe } \\
\text { Medications }\end{array}$ & $\begin{array}{c}\text { Perform } \\
\text { Intraocular } \\
\text { Surgery }\end{array}$ \\
\hline Optician & & & & & - & $x$ & - & - \\
\hline Optometrist (OD) & $x$ & $x$ & & & $x$ & $x$ & $x$ & $x$ \\
\hline $\begin{array}{l}\text { Ophthalmologist } \\
\text { (MD, DO) }\end{array}$ & $x$ & & $x$ & $x$ & $x$ & $x$ & $x$ & $x$ \\
\hline
\end{tabular}

Optometrists are allowed to perform intraocular surgery in 2 states in the United States. Other legislation is pending (eg, California SB 622). The medications that optometrists can prescribe are state dependent. There are optometric postgraduate training programs, but they are not mandatory.

diseases, eg, inflammation, infection, and neuronal degeneration. In other cases the pathology is unique to its function as a sensory organ exposed to the environment, eg, refractive errors, cataracts, strabismus, and some forms of ocular surface disease. Often diseases that affect the eye are a combination of both end organ and systemic diseases, eg, glaucoma, the pathology of which is a combination of systemic and ocular factors, or diabetic retinopathy, where the diabetic changes found elsewhere within the body affect the retina and can create blindness and visual disability. The local and direct nature of many treatments may allow more rapid development of novel pharmaceuticals and cell therapies than systemic diseases, as topical therapies do have systemic effects, but usually these are minimal at best. For example, topical $\beta$ adrenoceptor antagonists are associated with bradycardia and bronchoconstriction, and topical $\alpha$-adrenoceptor agonists are associated with sedation and systemic hypotension. Drug delivery systems are a particular need and area of intense research in ophthalmology. These delivery systems mirror those in general medicine, where we worry about absorption of medications (through the gut or through the cornea, or in special cases directly into the organ [inhalers, intrathecal, and intravitreal]). In this review we present pharmacological treatments for eye disease as well as iatrogenic conditions from treatment of systemic disease (eg, glaucoma from systemic corticosteroids or topiramate). As in many specialties, not all ophthalmic uses of medications are on-label. We do our best to point out when standard of care for some indications is off-label and to indicate usage differences in countries.

\section{General Ocular Considerations}

For most patients and eye care specialists, ocular therapeutics involve direct application of a medication (solutions, ointments, or gels) to the anterior surface of the eye. Poor or variable patient treatment adherence, especially with chronic diseases, is well known in almost all fields of medicine. ${ }^{3}$ However, good therapeutics with topical ocular medications is further challenged by patient performance. Instillation of eye drops is challenging for more than two-thirds of patients. ${ }^{4}$ Both opening the bottle, accurately squeezing a bottle, and delivering only a single drop to the eye can be challenging for many individuals, especially those who are elderly, have neurologic conditions, or have poor vision. Eye drops miss the eye, too many may be applied, and the dropper bottle and solution may become contaminated. Although there is little literature on ease of use of ophthalmic gels, in our experience, their application is more challenging than the application of eye drops. Patients have issues with the administration of an exact amount (without waste) and without contamination (eg, using fingers to place a specific amount of gel onto the eye). In addition, gels cause marked blurring for some period after instillation.

Ophthalmic preparations have challenging pharmaceutics, requiring a molecule with at least some aqueous solubility (weak acid/base) formulated in a concentrated form (30-50 $\mu \mathrm{L}$ for an eyedrop) at a tolerable acidity (typically near $\mathrm{pH} 7.4$, although both pilocarpine and dorzolamide are exceptions), and tonicity (typically near isotonic) with extended stability at room temperature or a "cold-chain" system. ${ }^{5}$ Doctors and their patients must be aware of refrigeration requirements, especially as these differ with seemingly similar products (eg, among the prostaglandin analogues). Regrettably, this is one of many items rarely discussed by doctors and pharmacists with their patients. ${ }^{6}$ Our guess is that the storage requirements are often not adhered to. The excipients (ie, inactives) used in the formulation must meet chemical and safety standards and should be without toxicity. Current standards require evaluation of particulates. Liquids may interact with plastic or glass containers and rubber stoppers, and thus, extensive evaluation of the containerclosure system is required. Leachables from packaging and labels are a concern for semipermeable bottles. Multidose containers require either preservatives (which may have toxicity) ${ }^{7}$ or a system to prevent contamination (21CFR200.50). ${ }^{8}$ Ophthalmic products are sterile, and thus, the integrity of the container-closure system is 
critical and must be tested. Injectable formulations have even more stringent pharmaceutics requirements, including evaluation for endotoxin and particulates. The USP standards for ophthalmic products are currently under review (eg, USP 771, 775, 789, etc; www.usp.org).

Although the age range of patients with ophthalmic conditions treated with pharmaceuticals can range from pediatric to geriatric, the majority of patients tend to be over 40 years of age. The geriatric population tends to have multiple comorbid diseases and concomitant medications. ${ }^{9}$ The eye has esterases and hydroxylases but relatively low levels of cytochrome P450 enzymes. Thus, drug-drug interactions are relatively minimal in the eye. There is a growing concern about drug transporter interaction in the eye. ${ }^{10,11}$ Most local ocular therapies have relatively low systemic absorption, although there are notable exceptions with some of the potent autonomic agents (eg, timolol ${ }^{12}$ and brimonidine ${ }^{13}$ ). There are always a few select patients who show systemic effects from medications that rarely demonstrate systemic adverse events (eg, an elevation of blood sugar or a steroid psychosis from topical corticosteroids). Local application is a key basis of the therapeutic index for some agents, minimizing the potential for systemic toxicity and drug-drug interactions. There are notable exceptions including the more potent vasoactive agents and corticosteroids. On the other hand, systemic therapies may have both therapeutic and toxic effects on the eye. For example, chronic systemic corticosteroid therapy may result in steroid-induced glaucoma and visual disability, and hydroxycholoroquinine can cause vision loss due to macular toxicity.

With respect to the pharmacology of the eye, it has extensive autonomic innervation. The cornea has a high density of innervation, presumably an evolutionary response to trauma. The retina has not only monaminergic synapses but also GABA and glutamate synapses.

\section{Drug Delivery}

The healthy eye is an immunologically privileged organ, partly as a result of the blood-eye and blood-retina barriers. ${ }^{14}$ Some of those anatomical barriers, as well as the performance issues noted above, make drug administration challenging. Thus, drug delivery is a very active area of research. Technologies used in marketed product and those in development include increased viscosity of eye drops as well as erodible or nonerodible implants placed subconjunctivally or intraocularly. ${ }^{2}$

\section{Pharmacokinetic/Pharmacodynamic Relationships and Pharmacogenomics}

Again, as a result of the anatomy, it is challenging to obtain samples of ocular tissue in patients in order to assess the ocular pharmacokinetics of either ocular or systemically administered drugs. The only exception might be obtaining aqueous samples in eyes where surgical procedures are planned. Thus, pharmacokinetics/ pharmacodynamics relationships are relatively poorly understood in the human eye. There are presumed genetic bases for ocular pathology (eg, retinitis pigmentosa, intraocular pressure response to chronic corticosteroid therapy, and age-related macular degeneration). Howev$\mathrm{er}$, there is limited pharmacogenomics information. ${ }^{15}$ That said, there is growing evidence for some genetic basis for disease progression and the response to intravitreally injected inhibitors of VEGF. ${ }^{16,17}$

\section{Infection (Bacterial, Viral, Fungal)}

The anterior, external surface of the eye is in direct contact with the environment and thus subject to infections and allergens. The inside of the eye, although protected, is also subject to infection in certain disease states as well as from iatrogenic sources (intraocular surgery, intraocular injections, trauma, or systemic infections). Topical ocular formulations (solutions, gels, suspensions) are available for a wide range of antibiotics including chloramphenicol, aminoglycosides, macrolides, and, more recently, a wide range of fluoroquinolones. Most of these agents are approved only for the indication of bacterial conjunctivitis, with the exception of ciprofloxacin, ofloxacin, and the higher concentration of levofloxacin, which are approved for the treatment of corneal ulcers. Note that none is approved for bacterial blepharitis (inflammation of the oil glands associated with eyelashes on the eye lid margin). One of the most frequent uses of topical antibiotics, postsurgical prophylaxis of endophthalmitis (a rare sightthreatening condition), is off-label in the United States because to date minimal evidence is available to justify its use. ${ }^{18}$ In the European Union, cefixime is marketed for this indication. ${ }^{19}$ A retrospective evaluation in the United States supports use of antibiotics for this prophylactic use, ${ }^{20}$ although controlled prospective data are limited at best. In addition, surgeons are also applying marketed topical antibiotics by a number of methods at the time of surgery (eg, intracameral injection of fluoroquinolones). ${ }^{21}$

Fungal infections of the eye are also known but relatively rare. These are most common in patients wearing extended-wear contact lenses and are becoming more frequent following corneal transplantation surgeries. ${ }^{22}$ Fungal infections are also seen following trauma to the cornea or penetration trauma to the globe. Natamycin is the only approved ocular agent in the United States, and propamidine isethionate is available in the European Union. In 2004-2006, there was a widespread Fusarium keratitis epidemic associated with manufacturing issues of selected contact lens care products. ${ }^{23}$

Currently, 2 antiviral agents, idoxuridine and trifluorothymidine, are approved for use in the treatment of 
herpetic keratitis. Cytomegalovirus infection of the retina was a common end-stage condition in patients with AIDS prior to the advent of protease inhibitors. There are several agents approved for this indication-cidofovir (intravitreal), valganciclovir (oral), ganciclovir (the first approved intraocular implant for placement in the vitreous cavity), ${ }^{24,25}$ and fomivirsen (intravitreal, the first approved antisense drug) ${ }^{26}$ There is no approved therapy for adenoviral conjunctivitis (also known as epidemic keratoconjunctivitis), although several antivirals such as cidofovir have been evaluated. Topical corticosteroids may be administered to alleviate the pain and light sensitivity, yet they are felt to increase the duration of the disease.

\section{Ocular Surface Disease}

Tears have three main components: aqueous (from the primary and accessory lacrimal glands), mucin (from goblet cells in the conjunctiva), and meibum (oils from the meibomian glands on the eyelids). Patients with "dry eye," also known as keratoconjunctivitis sicca, and more generally ocular surface disease have signs and symptoms resulting from inadequate tear production and imperfect coating of the cornea by the tear film. ${ }^{27}$ More recently, meibomian gland disease (also known as anterior blepharitis) has been recognized to be a major component for some of these patients. ${ }^{28}$ There are at least 5 million patients in the United States with dry eye disease, more frequent in women (especially postmenopausal). ${ }^{29}$ The etiology of ocular surface disease is rarely known, and the presentation is variable.

There is a hierarchy of treatments for ocular surface disease, and often the treatment is empiric. Initially, patients are usually given tear supplementation. If this is inadequate, they are then educated about possible environmental factors, evaluated for possible adverse events from systemic medications (eg, drying from antimuscarinics), and treated with over-the-counter artificial tear substitutes and eyelid scrubs. These are regulated in the United States as noted in a monograph (21 CFR 349). Patients may then proceed to a variety of both pharmacological treatments (cyclosporine in the United States and the European Union, secretogogues [rebamipide, hyaluronic acid, and diquafasol in Japan]), ${ }^{30}$ and physical supplementations such as punctal plugs and moisture chamber spectacles. More severe patients are treated with ocular and systemic anti-inflammatory (possibly macrolide) agents and surgical modification of the tear flow system. ${ }^{31}$ In very severe cases that are recalcitrant to other therapies, the puncta are cauterized to permanently occlude them so that all of the tears stay on the ocular surface.

Given the multifactorial nature of dry eye disease, many have theorized about various possible pharmacological treatments. Unfortunately, most have been unsuccessful in yielding meaningful benefits in signs and symptoms over the vehicle alone. ${ }^{32}$ At present, there are several agents in late-stage development. ${ }^{33}$

\section{Glaucoma}

Glaucoma is an optic neuropathy characterized by an intraocular pressure (IOP) that is too elevated for a specific eye, causing loss of retinal ganglion cells with corresponding peripheral vision (visual field) loss. Glaucoma is the second leading cause of blindness in blacks and Hispanics and the third leading cause of blindness in whites. ${ }^{34,35}$ Primary open-angle glaucoma most commonly progresses slowly, over years, so that patients are unaware of any damage. Central vision is the last to go, causing this to be undetected by the patient until there is significant functional loss such as the inability to drive, the cessation of driving, difficulties with facial recognition, trouble walking, less daily activity, and difficulties reading. ${ }^{36,37}$ Ocular hypertension (often known as glaucoma suspect) is an elevated IOP greater than 2 standard deviations from the mean without apparent neuronal or functional loss. The components are the production of aqueous humor, the outflow through the trabecular meshwork, the outflow through other routes (uveoscleral outflow), and the background episcleral pressure. Lowering of IOP by pharmaceutical agents, laser treatment of the outflow channels (trabeculoplasty), or surgical means decreases the rate of progression of glaucomatous visual field loss. ${ }^{38-41}$ The American Academy of Ophthalmology's Preferred Practice patterns suggest that all newly diagnosed glaucoma patients be given a choice of medical, laser, or surgical therapy. ${ }^{42}$ Although all methods have been shown to be effective, in most developed countries, pharmacological therapy is almost always the initial approach. ${ }^{42-44}$ Current therapy involves a "set point"- targeting an IOP at which clinicians believe, based on published clinical evidence, that further glaucomatous progression is minimized. ${ }^{45}$

Primary glaucoma surgery most commonly involves creating a new outflow pathway either by creating a halfthickness flap in the sclera (trabeculectomy) or inserting a tube into the anterior chamber that is connected to an external reservoir. Most glaucoma surgeons would perform the split-thickness opening first and employ the tube in selected types of glaucoma as a primary surgical procedure or if the initial trabeculectomy fails. A metabolite, mitomycin $\mathrm{C}$, is often employed to increase the success rate of the trabeculectomy. However, the use of this agent is associated with excessively low IOP, choroidal detachments, and cataract formation. ${ }^{46,47}$ In glaucoma surgery, mitomycin is used at the time of the procedure in order to decrease the fibroblast reaction and thus increase the long-term patency of the surgery. ${ }^{48}$ 
In patients with primary open-angle glaucoma, the pathophysiology is a susceptible optic nerve that is damaged due to elevated IOP. The determinants of IOP are described in an equation by Goldmann ${ }^{49}$ (as cited in Brubaker). ${ }^{50}$ These determinants are the amount of fluid created by the ciliary body and the ability of the trabecular meshwork to handle this fluid, as well as uveoscleral outflow. Thus, ideally, pharmacological therapy should be aimed at increasing trabecular outflow. However, to date, only 1 approved agent has been shown to increase trabecular outflow in humans - pilocarpine. In addition to miosis, pilocarpine causes loss of accommodation (a problem more common in younger patients) and is very short-lived, requiring 4-times-daily dosing. Rho kinase inhibitors, one of which is approved in Japan (ripasudil) and others in development in the United States, are also thought to increase trabecular outflow. ${ }^{51-56}$

In developed countries, the first choice for pharmacological lowering of IOP is usually a prostaglandin analogue-latanoprost, bimatoprost, tafluprost, travoprost, or unoprostone. These are once-daily (evening) treatments, with systemic adverse events and usually tolerable ocular side effects. The most common adverse event is conjunctival hyperemia, seen in approximately $5 \%-15 \%$ of patients with the first and $25 \%-50 \%$ with the last 3 agents. Other adverse events of note include eyelid pigmentation, periorbital fat atrophy, and eyelash growth. All of these are now thought to be related to the pharmacology of prostaglandin analogues. Prostaglandin analogues lower intraocular pressure by increasing uveoscleral outflow. ${ }^{57,58}$ In general, the order of ocular hypotensive efficacy is bimatoprost $>$ travoprost $\geq$ latanoprost $>$ tafluprost $>$ unoprostone.

Other agents are used, typically as second or later line therapies depending on the patient unless there are sensitivities or allergies to prostaglandin analogues. Frequently used are nonselective $\beta$-adrenoceptor antagonists (eg, timolol, levobunolol, carteolol, and metoprolol as well as the relatively selective $\beta_{1-\text { adrenoceptor }}$ antagonist, betaxolol). These agents are used once or twice daily and lower intraocular pressure by reducing aqueous humor production. ${ }^{59,60}$ Another class of agents, are topical carbonic anhydrase inhibitors (dorzolamide, brinzolamide) that are somewhat less effective than $\beta$ adrenoceptor antagonists. ${ }^{61,62}$ This class also acts by reducing aqueous humor production. Systemic carbonic anhydrase inhibitors were used prior to the availability of topical agents. However, the dose that lowers IOP also inhibits carbonic anhydrase throughout the body, and thus, these agents are typically reserved for advanced patients at this time. Only approximately one-third of patients can tolerate systemic carbonic anhydrase inhibitors for a month or more. ${ }^{63}$

Also used are adrenergic agonists. Starting in the $1930 \mathrm{~s}$, topical epinephrine (an $\alpha_{1^{-}}$and $\beta_{1} / \beta_{2^{-}}$ adrenoceptor agonist) and its prodrug, dipivalyl epinephrine in the 1980s, were used. An aqueous humor dynamic study suggests that epinephrine increases aqueous humor production (which would increase IOP) but also increases uveoscleral outflow. ${ }^{59}$ Given the limited ocular hypotensive efficacy, as well as ocular and systemic adverse events, these agents are rarely used today and are not available in the United States.

Adrenergic agonists with activity at the $\alpha_{1}$ and $\alpha_{2}$ adrenoceptor were developed in the late 1980s and 1990s. Apraclonidine, a mixed $\alpha_{1}-\alpha_{2}$ agonist, lowers IOP primarily through a reduction in aqueous humor production. ${ }^{64}$ Its ocular hypotensive effect shows tolerance, and so its current practice is primarily for short-term dosing after laser procedures. Its effect as an $\alpha_{1}$-adrenoceptor agonist has advantages when performing ND:YAG laser iridotomies. Pretreatment with apraclonidine lessens bleeding, which can complicate this procedure. ${ }^{65}$ Brimonidine, primarily an $\alpha_{2}$ agonist, lowers IOP by decreasing aqueous flow and also increasing uveoscleral outflow. ${ }^{66}$ Brimonidine is typically not a first-line agent but is used today in addition to other agents, either in separate bottles or in fixed-dose combination.

Cannabinoids, inhaled or ingested, lower IOP, although there are no controlled head-to-head studies against approved topical agents. The duration of activity is short. Cardiovascular and neurological effects are observed at the same dose and may theoretically reduce the beneficial effect of lowering IOP by reducing ocular blood flow. Thus, the benefit-risk of available cannabinoids is relatively low. ${ }^{67}$

For approximately half of the patients under therapy, a single medication is inadequate to maintain an adequate IOP. ${ }^{38}$ The standard practice is to add additional agents. $^{42-44}$ This plus the issues with adherence have led to the development of several fixed-dose combinations as adherence diminishes with an increasing number of glaucoma medications needed. ${ }^{68}$ The US FDA has enforced the "combination rule" (21 CFR 300.50), requiring the fixed-dose combination to be more effective than either of the agents used by itself. For the fixed-dose combinations with prostaglandins, FDA has judged that there was inadequate data to provide a clinically significant additivity that outweighs the risks, ${ }^{69}$ although such combinations are approved in Europe, South America, and Asia. Other fixed-dose combinations available worldwide include timolol and dorzolamide, timolol and brimonidine, brimonidine and brinzolamide, and a triple combination of timolol, dorzolamide, and brimonidine.

\section{Inflammation, Allergy, and Surgery}

The eye can be exquisitely sensitive to trauma, responding with an inflammatory cascade. Rabbits, known to be hyperimmune system responders, when stimulated in 1 
eye with a corneal touch, will show anterior chamber cloudiness (a sign of blood-aqueous barrier breakdown) in the fellow eye. ${ }^{70}$ The primary treatment for ocular inflammation includes corticosteroids. These include topical ocular formulations of a wide-range of corticosteroids from the low-potency medrysone to the higher potency dexamethasone, prednisolone acetate, and difluprednate. Eye care professionals are concerned about both the systemic effects (raising of blood glucose levels) ${ }^{71}$ and the known ocular adverse events with chronic corticosteroids - cataract and glaucoma. ${ }^{72}$ Thus, the duration of treatment is aimed to be kept short. Fluorometholone, of lower potency, is also known to have limited intraocular penetration in humans and thus is used for external conditions. ${ }^{73}$ Loteprednol etabonate, a "siteactive" corticosteroid, was designed to be rapidly metabolized by ocular esterases to inactive molecules ${ }^{74}$ and is approved for the treatment of numerous external and anterior segment inflammatory conditions. In the United States several ocular corticosteroids have a broad approval for "corticosteroid-responsive conditions" through the Drug Efficacy Study (DESI). This allows for labeling for conditions for which no studies have been performed (eg, iritis). ${ }^{75,76}$ As with all eyedrops, ocular corticosteroids may be absorbed systemically in sufficient quantities to elicit systemic effects.

Uveitis is a potentially sight-threatening inflammatory condition that may be found in the anterior and/or posterior portions of the eye. It has a wide range of etiologies and may be infectious or noninfectious. Often, despite exhaustive workups, the etiology remains unknown. Anterior uveitis is typically initially treated with topical corticosteroids. Topical treatments typically do not reach the posterior segment, and thus, posterior uveitis may often be treated by injected corticosteroids (triamcinolone acetonide as Triescence ${ }^{\circledR}$, Trivaris ${ }^{\circledR}$, or off-label Kena$\log ^{\circledR}$ ) or implanted intraocular drug delivery systems (fluocinolone acetonide, Retisert ${ }^{\mathrm{TM}}, 3$ years' duration, ${ }^{77}$ or dexamethasone, Ozurdex ${ }^{\circledR}, 3-6$ months' duration). ${ }^{78}$

Nonsteroidal anti-inflammatory drugs (NSAIDs) are used extensively in ophthalmology, most commonly offlabel. The first approved indication in the United States was a prophylaxis before cataract surgery to maintain pupil area for topical ocular flurbiprofen. ${ }^{79}$ In the years since, a number of NSAIDs have been approved for topical use for treatment of postoperative inflammation and pain following corneal refractive procedures. Topical ketorolac was reported to treat cystoid macular edema. ${ }^{80,81}$ Topical NSAIDs are used today postoperatively to prevent the occurrence of cystoid macular edema, although this indication is off-label, and there are few recent controlled data to support this indication.

Allergic conjunctivitis is a relatively common condition, often due to environmental allergens. It is typically treated with topical ocular antihistamines (ketotifen, olopatadine, etc.), as well as prophylactic mast cell stabilizers (cromoglycate, amlexanox). Many of these agents are available over the counter. Some agents may also have antimuscarinic properties, which inadvertently may lead to signs and symptoms of dry eye disease. Corticosteroids are also approved for ocular allergy, but the ocular adverse events of chronic corticosteroid (IOP elevation and cataract formation) use typically limit their use to patients with severe disease.

Many pharmaceutical agents are used during and after ophthalmic surgery. In addition to the topical use of NSAIDs and antibiotics as noted previously, corticosteroids are also used both pre- and postoperatively to prevent inflammation. Control of the pupil is key to visualizing the eye during surgery. Treatments used include preoperative muscarinic antagonists (cyclopentolate, tropicamide) and adrenergic agonists (eg, epinephrine, phenylephrine) to dilate the pupil, and intraoperative cholinergic agonists (eg, acetylcholine, carbachol) to constrict the pupil. Viscoelastics (eg, hyaluronic acid) are used during surgery to facilitate certain procedures, ${ }^{82}$ although these are regulated as devices. NSAIDs, cholinergic agents, and antimicrobials are also instilled into the anterior chamber (intracameral), although this is typically off-label. Recently, a fixed combination of an NSAID (ketorolac) and phenylephrine has been approved in the United States for intracameral use during cataract surgery. This agent may help maintain pupil dilation during surgery while reducing postoperative pain.

\section{Retinal Degeneration and Macular Edema}

The retina is an extremely complex, 10-layered, hierarchical structure containing neurons, glia, and blood vessels. The retina is the photosensitive portion of the eye. The fovea, a small area $1.5 \mathrm{~mm}$ in diameter provides the resolution for fine vision (reading) and color vision. Whereas some signal processing occurs in the retina, it is really the brain where a human "sees." There are a host of retinal diseases, of which some occur at birth, some are acquired, some are genetic in origin, and some are related to aging. Some of the acquired diseases are anatomical (eg, retinal detachment or persistent hyperplastic primary vitreous) and thus can be surgically treated. Some of the diseases are infectious, eg, cytomegalovirus retinitis, and thus can be treated with antimicrobial drugs (intravitreal ganciclovir, as noted above). For some diseases of single Mendelian genetic origin, although there is no approved therapy, there are investigational gene transfer treatments (retinitis pigmentosa/Leber's congenital amaurosis due to RPE65 mutation, and choroideremia). ${ }^{83,84}$ The recently approved ocriplasmin can induce a vitreous detachment, which may be indicated in certain conditions where the vitreous pulls on the retina. ${ }^{85}$ 
The macula, the most sensitive area of human vision, may degenerate with age. There are few treatments for this condition for which the major risk factors are genetics, age, sun exposure, and tobacco smoking. However, prophylactic treatment of patients with mild to moderate disease with a fixed high-dose combination of several micronutrient antioxidants (vitamin C; vitamin E; $\beta$-carotene, an analogue of Vitamin A; zinc oxide; and cupric oxide) slows down progression. ${ }^{86}$ In primates the vasculature to supply the macula is anterior to the photoreceptors, that is, between the light source and the photoreceptors. Thus, in advanced macular degeneration, in response to the retina releasing VEGF, the choroid creates neovascularization, which in turn reduces visual function. At one time choroidal neovascularization was treated with laser, which unfortunately also damaged the underlying photoreceptors and could act as a stimulus for further neovascularization. In the 1990s, a photodynamic therapy was approved. Verteporfin, administered intravenously, is activated by a broad nonthermal laser, and releases activated oxygen, which destroys these vessels. ${ }^{87}$ In the mid-2000s, the role of VEGF and its inhibition became better understood, with the approval of pegaptanib, an aptamer. Today, intravitreal injections of VEGF inhibitors (ranibizumab, aflibercept, and the off-label use of bevacizumab) are the standard of care for patients with choroidal neovascularization as well as addition retinal indications. VEGF also has a role in edema related to diabetes and retinal vein occlusion, and several of these agents are approved for these indications as well. Most recently, ranibizumab was approved for the treatment of diabetic retinopathy associated with diabetic macular edema. ${ }^{88}$ Unfortunately, for most of the other retinal diseases, especially those related to degeneration of neurons or glial, there is no approved treatment. In this way, these diseases are ocular analogues of the neuronal conditions of senile dementia and Parkinson disease.

\section{Strabismus and Blepharospasm}

Strabismus, misalignment of the external ocular muscles, is typically treated by surgical means. Approximately 35 years ago, Scott proposed therapeutic use of locally injected botulinum toxin (OnabotulinumtoxinA), an agent that stops transmission across cholinergic synapses, for strabismus. ${ }^{89}$ Subsequently, botulinum toxin was also evaluated and approved for blepharospasm. ${ }^{90}$

\section{Refractive Errors}

Key to the high level of visual functioning in humans is a high-resolution image on the retina. This requires the entire eye, from the cornea through the anterior chamber, lens, and vitreous, to be clear so that an image can be clearly focused on the retina. If the eye is too long (myopia) or too short (hyperopia), then the image will not be focused on the retina. Likewise, if either the lens or cornea does not refract light in a spherical manner but more like an Australian or American football, the image again is distorted, and this induces "astigmatism." These conditions are treated with spectacles, contact lenses, laser, refractive surgery, or intraocular surgery (with placement of appropriate intraocular lenses). However, prophylactic treatment of children with mild myopia with either topical ocular low-dose atropine ${ }^{91}$ or pirenzepine ${\text { (an } \mathrm{M}_{1} \text {-specific antimuscarinic) }}^{92,93}$ has been shown to reduce the rate of myopic progression by about $50 \%$ without substantial ocular antimuscarinic effects (eg, mydriasis and loss of accommodation). Low-dose atropine is currently marketed for this indication in Singapore. The loss of accommodation caused by highdose atropine is used therapeutically to create monocular blur ("penalization") and to treat pediatric amblyopia. 94 Atropine is approved in the United States for this indication.

\section{Summary}

The complexity of both the eye and visual function leads to a wide variety of ocular pathology. Some of the ocular pathology can be treated or prevented by pharmacological therapy. Local ocular therapy often provides a differential therapeutic index over systemic therapy by reducing the potential for systemic toxicity. Although some pharmacological agents have been used since before 1900 (eg, atropine and pilocarpine), others are relatively new (eg, VEGF-inhibitors). Ongoing research includes diverse areas such as ophthalmic drug delivery (to deal with treatment adherence and performance issues), prophylaxis of dry age-related macular degeneration, geographic atrophy, and neurodegeneration.

\section{Disclosure}

Drs Novack and Robin consult for numerous pharmaceutical and medical device firms. Dr Robin has stock options in Glaukos and Aerie Pharmaceuticals.

\section{Funding}

None.

\section{References}

1. Goss CM. The Organs of the Senses, 29th ed. Philadelphia: Lea \& Febiger, 1973.

2. Novack GD. Ophthalmic drug delivery: development and regulatory considerations. Clin Pharmacol Ther. 2009;85:539-543.

3. Blaschke TF, Osterberg L, Vrijens B, Urquhart J. Adherence to medications: insights arising from studies on the unreliable link between prescribed and actual drug dosing histories. Annu Rev Pharmacol Toxicol. 2011;52:275-301. 
4. Stone JL, Robin AL, Novack GD, Covert D, Cagle GD. An objective evaluation of eye-drop instillation in glaucoma patients. Arch Ophthalmol. 2009;127:732-736.

5. Edman P. Biopharmaceutics of Ocular Drug Delivery (Pharmacology and Toxicology). Boca Raton, FL: CRC Press; 1993.

6. Sleath B, Blalock SJ, Carpenter DM, et al. Ophthalmologist-patient communication, self-efficacy, and glaucoma medication adherence. Ophthalmology. 2015;122:748-754.

7. Baudouin C, Labbe A, Liang H, Pauly A, Brignole-Baudouin F. Preservatives in eyedrops: the good, the bad and the ugly. Prog Retin Eye Res. 2010;29:312-334

8. Brown RH, Novack GD. General principles of ophthalmic medications. In: Morrison J, Pollack I, eds. Glaucoma: Science and Practice. New York: Thieme Publishing Company, 2002;354-362.

9. Covert D, Robin AL, Novack GD. Systemic medications and glaucoma patients (letter). Ophthalmology. 2005;112:1849-1853.

10. Zhang T, Xiang CD, Gale D, Carreiro S, Wu EY, Zhang EY. Drug transporter and cytochrome P450 mRNA expression in human ocular barriers: implications for ocular drug disposition. Drug Metab Dispos. 2008;36:1300-1307.

11. Kraft ME, Glaeser H, Mandery $\mathrm{K}$, et al. The prostaglandin transporter OATP2A1 is expressed in human ocular tissues and transports the antiglaucoma prostanoid latanoprost. Invest Ophthalmol Vis Sci. 2010;51:2504-2511.

12. van Buskirk EM. Adverse reactions from timolol administration. Ophthalmology. 1980;87:447-450.

13. Nordlund JR, Pasquale LR, Robin AL, et al. The cardiovascular, pulmonary, and ocular hypotensive effects of $0.2 \%$ brimonidine. Arch Ophthalmol. 1995;113:77-83.

14. Streilein JW. Ocular immune privilege: therapeutic opportunities from an experiment of nature. Nat Rev Immunol. 2003;3:879-889.

15. Novack GD. Pipeline: thoughts generated by the Annual Meeting of the American Society of Clinical Pharmacology and Therapeutics. Ocul Surf. 2004;2:212-214.

16. Perlee LT, Bansal AT, Gehrs K, et al. Inclusion of genotype with fundus phenotype improves accuracy of predicting choroidal neovascularization and geographic atrophy. Ophthalmology. 2013;120:1880-1892.

17. Fauser S, Lambrou GN. Genetic predictive biomarkers of antiVEGF treatment response in patients with neovascular age-related macular degeneration. Surv Ophthalmol. 2015;60:138-152.

18. Ciulla TA, Starr MB, Masket S. Bacterial endophthalmitis prophylaxis for cataract surgery: an evidence-based update. Ophthalmology. 2002;109:13-24.

19. Group EES. Prophylaxis of postoperative endophthalmitis following cataract surgery: results of the ESCRS multicenter study and identification of risk factors. J Cataract Refract Surg. 2007;33: 978-988.

20. Shorstein NH, Winthrop KL, Herrinton LJ. Decreased postoperative endophthalmitis rate after institution of intracameral antibiotics in a Northern California eye department. J Cataract Refract Surg. 2013;39:8-14.

21. Packer M, Chang DF, Dewey SH, et al. Prevention, diagnosis, and management of acute postoperative bacterial endophthalmitis. $J$ Cataract Refract Surg. 2011;37:1699-1714.

22. Buehler PO, Schein OD, Stamler JF, Verdier DD, Katz J. The increased risk of ulcerative keratitis among disposable soft contact lens users. Arch Ophthalmol. 1992;110:1555-1558.

23. Bullock JD, Warwar RE, Elder BL, Northern WI. Temperature instability of ReNu With MoistureLoc: a new theory to explain the worldwide Fusarium keratitis epidemic of 2004-2006. Arch Ophthalmol. 2008;126:1493-1498.

24. Martin DF, Parks DJ, Mellow SD, et al. Treatment of cytomegalovirus retinitis with an intraocular sustained-release ganciclovir implant. Arch Ophthalmol. 1994;112:1531-1539.
25. Musch DC, Martin DF, Gordon JF, Davis MD, Kuppermann BD. Treatment of cytomegalovirus retinitis with a sustained-release ganciclovir implant. The Ganciclovir Implant Study Group. N Engl J Med. 1997;337:83-90.

26. Group TVS. A randomized controlled clinical trial of intravitreous fomivirsen for treatment of newly diagnosed peripheral cytomegalovirus retinitis in patients with AIDS(1). Am $J$ Ophthalmol. 2002;133:467-474.

27. Foulks GN. DEWS report: a mission completed. Ocul Surf. 2007;5:65-66.

28. Nichols KK, Foulks GN, Bron AJ, et al. The international workshop on meibomian gland dysfunction: executive summary. Invest Ophthalmol Vis Sci. 2011;52:1922-1929.

29. Smith JA, Albeitz J, Begley C, et al. The epidemiology of dry eye disease: report of the Epidemiology Subcommittee of the International Dry Eye WorkShop (2007). Ocul Surf. 2007;5: 93-107.

30. Sullivan DA, Hammitt KM, Schaumberg DA, et al. Report of the TFOS/ARVO Symposium on Global Treatments for Dry Eye Disease: an unmet need. Ocul Surf. 2012;10:108-116.

31. Pflugfelder SC, Geerling G, Kinoshita S, et al. Management and therapy of dry eye disease: report of the Management and Therapy Subcommittee of the International Dry Eye WorkShop (2007). Ocul Surf. 2007;5:163-178.

32. Novack GD. Pipeline: why aren't there more pharmacotherapies for dry eye? Ocul Surf. 2014;12:227-230.

33. Sheppard JD, Torkildsen GL, Lonsdale JD, et al. Lifitegrast ophthalmic solution $5.0 \%$ for treatment of dry eye disease: results of the OPUS-1 phase 3 study. Ophthalmology. 2014;121:475-483.

34. Friedman DS, Wolfs RC, O'Colmain BJ, et al. Prevalence of openangle glaucoma among adults in the United States. Arch Ophthalmol. 2004;122:532-538.

35. Jiang X, Varma R, Wu S, et al. Baseline risk factors that predict the development of open-angle glaucoma in a population: the Los Angeles Latino Eye Study. Ophthalmology. 2012;119:2245-2253.

36. Hochberg C, Maul E, Chan ES, et al. Association of vision loss in glaucoma and age-related macular degeneration with IADL disability. Invest Ophthalmol Vis Sci. 2012;53:3201-3206.

37. Ramulu P. Glaucoma and disability: which tasks are affected, and at what stage of disease? Curr Opin Ophthalmol. 2009;20:92-98.

38. Kass MA, Heuer DK, Higginbotham EJ, et al. for the Ocular Hypertension Treatment Study Group. The Ocular Hypertension Treatment Study: a randomized trial determines that topical ocular hypotensive medication delays or prevents the onset of primary open-angle glaucoma. Arch Ophthalmol. 2002;120:701-713.

39. Heijl A, Leske MC, Bengtsson B, et al. Reduction of intraocular pressure and glaucoma progression: results from the early manifest glaucoma trial. Arch Ophthalmol. 2002;120:1268-1279.

40. Group GLTR. The Glaucoma Laser Trial (GLT) and Glaucoma Laser Trial follow-up study: 7. Results. Am J Ophthalmol. 1995;120:718-731.

41. Lichter PR, Musch DC, Gillespie BW, et al. Interim clinical outcomes in the Collaborative Initial Glaucoma Treatment Study comparing initial treatment randomized to medications or surgery. Ophthalmology. 2001;108:1943-1953.

42. Panel AAO. Preferred Practice Pattern: Primary Open-Angle Glaucoma. San Francisco, CA: American Academy of Ophthalmology; 2010. http://www.aao.org/preferred-practice-pattern/primary-openangle-glaucoma-ppp--october-2010.

43. Panel AAO. Preferred Practice Pattern: Primary Open-Angle Glaucoma Suspect. San Francisco, CA: American Academy of Ophthalmology; 2010. http://www.aao.org/preferred-practice-pattern/primary-openangle-glaucoma-suspect-ppp--october-20.

44. Society EG. Terminology and Guidelines for Glaucoma, 4th ed. Savona, Italy: PubliComm; 2014. 
45. Singh K, Sit AJ. Intraocular pressure variability and glaucoma risk: complex and controversial. Arch Ophthalmol. 2011;129:1080-1081.

46. Gedde SJ, Schiffman JC, Feuer WJ, Herndon LW, Brandt JD, Budenz DL. Treatment outcomes in the tube versus trabeculectomy (TVT) study after five years of follow-up. Am J Ophthalmol. 2012;153:789-803.

47. Budenz DL, Barton K, Feuer WJ, et al. Treatment outcomes in the Ahmed Baerveldt Comparison Study after 1 year of follow-up. Ophthalmology. 2011;118:443-452.

48. Robin AL, Ramakrishnan R, Krishnadas R, et al. A long-term doseresponse study of mitomycin in glaucoma filtration surgery. Arch Ophthalmol. 1997;115:969-974.

49. Goldmann H. Out-flow pressure, minute volume and resistance of the anterior chamber flow in man. Doc Ophthalmol $A d v$ Ophthalmol. 1951;5-6:278-356.

50. Brubaker RF. Goldmann's equation and clinical measures of aqueous dynamics. Exp Eye Res. 2004;78:633-637.

51. Bacharach J, Dubiner HB, Levy B, Kopczynski CC, Novack GD, Group A-CS. Double-masked, randomized, dose-response study of AR-13324 vs. latanoprost in patients with elevated intraocular pressure. Ophthalmology. 2015;122:302-307.

52. Kiel JW, Kopczynski C. Effect of AR-13324 on episcleral venous pressure in Dutch belted rabbits. J Ocul Pharmacol Ther. 2015;31:146-151.

53. Wang R-F, Williamson JE, Kopczynski C, Serle JB. Effect of 0.04\% AR-13324, a ROCK and norepinephrine transporter inhibitor, on aqueous humor dynamics in normotensive monkey eyes. J Glaucoma. 2015;24:51-54.

54. Williams RD, Novack GD, van Haarlem T, Kopczynski C; AR12286 Phase 2A Study Group. Ocular hypotensive effect of the Rho kinase inhibitor AR-12286 in patients with glaucoma and ocular hypertension. Am J Ophthalmol. 2011;152:834-841.e1.

55. Tanihara $\mathrm{H}$, Inoue $\mathrm{T}$, Yamamoto $\mathrm{T}$, Kuwayama $\mathrm{Y}$, Abe H, Araie M. Phase 2 randomized clinical study of a rho kinase inhibitor, K-115, in primary open-angle glaucoma and ocular hypertension. $\mathrm{Am} \mathrm{J}$ Ophthalmol. 2013;156:731-736.

56. Tanihara H, Inatani M, Honjo M, Tokushige H, Azuma J, Araie M. Intraocular pressure-lowering effects and safety of topical administration of a selective ROCK inhibitor, SNJ-1656, in healthy volunteers. Arch Ophthalmol. 2008;126:309-315.

57. Toris CB, Camras CB, Yablonski ME. Effects of PhXA41, a new prostaglandin F2 alpha analog, on aqueous humor dynamics in human eyes. Ophthalmology. 1993;100:1297-1304.

58. Weinreb RN, Toris CB, Gabelt BT, Lindsey JD, Kaufman PL. Effects of prostaglandins on the aqueous humor outflow pathways. Surv Ophthalmol. 2002;47 Suppl 1:S53-S64.

59. Schenker HW, Yablonski ME, Podos SM, et al. Fluorophotometric study of epinephrine and timolol in human subjects. Arch Ophthalmol. 1981;99:1212-1226.

60. Coakes RL, Brubaker RF. The mechanism of timolol in lowering intraocular pressure. Arch Ophthalmol. 1978;96:2045-2048.

61. Strahlman E, Tipping R, Vogel R. A double-masked, randomized 1year study comparing dorzolamide (Trusopt), timolol, and betaxolol. International Dorzolamide Study Group. Arch Ophthalmol. 1995;113:1009-1016.

62. Adamsons I, Clineschmidt C, Polis A, et al. The efficacy and safety of dorzolamide as adjunctive therapy to timolol maleate gellan solution in patients with elevated intraocular pressure. J Glaucoma. 1998;7:253-260.

63. Lichter PR, Newman LP, Wheeler NC, Beall OV. Patient tolerance to carbonic anhydrase inhibitors. Am J Ophthalmol. 1978;85: $495-502$.

64. Gharagozloo NZ, Relf SJ, Brubaker RF. Aqueous flow is reduced by the alpha-adrenergic agonist, apraclonidine hydrochloride (ALO 2145). Ophthalmology. 1988;95:1217-1220.
65. Robin AL. The role of apraclonidine hydrochloride in laser therapy for glaucoma. Trans Am Ophthalmol Soc. 1989;87:729-761.

66. Toris CB, Gleason ML, Camras CB, Yablonski ME. Effects of brimonidine on aqueous humor dynamics in human eyes. Arch Ophthalmol. 1995;113:1514-1517.

67. Novack GD. Medicinal cannabis for glaucoma. Curr Opin Ophthalmol. in press.

68. Robin AL, Novack GD, Covert DW, Crockett RS, Marcic TS. Adherence in glaucoma: objective measurements of once-daily and adjunctive medication use. Am $J$ Ophthalmol. 2007;144: 533-540.

69. Novack GD. Pipeline: what does it mean when a company says that a product is "approvable"? Ocul Surf. 2005;3:63-64.

70. Jesner S. Der humor aqueus des Auges in seinen beziehungen zu blutdruck und nerventreizung. Pflugers Arch Eur J Physiol. 1880 23:14-44.

71. Feldman-Billard S, Dupas B, Sedira N, et al. Hypoglycaemia is associated with the absence of a decrease in diurnal macular thickness in patients with diabetic macular oedema. Diabetes Metab. 2013;39:169-173

72. Yablonski ME, Burde RM, Kolker AE, Becker B. Cataracts induced by topical dexamathasone in diabetics. Arch Ophthalmol. 1978;96:474-476.

73. Fairbairn WD, Thorson JC. Fluorometholone: anti-inflammatory and intraocular pressure effects. Arch Ophthalmol. 1971;86: 138-141.

74. Bodor N. Soft drugs: principles and methods for the design of safe drugs. Med Res Rev. 1984;4:449-469.

75. Novack GD. Pipeline: decoding the package insert: indications. Ocul Surf. 2003;1:150-151.

76. Cannan RK. The Drug Efficacy Study of the National Research Council's Division of Medical Sciences, 1966-1969, 1968. Washington, DC: National Academy of Sciences. http://www. nasonline.org/about-nas/history/archives/collections/des-19661969-1.html?referrer=https://www.google.com/.

77. Jaffe GJ, Ben Nun J, Guo H, Dunn JP, Ashton P. Fluocinolone acetonide sustained drug delivery device to treat severe uveitis. Ophthalmology. 2000;107:2024-2033.

78. Lowder C, Belfort R Jr, Lightman S, et al. Dexamethasone intravitreal implant for noninfectious intermediate or posterior uveitis. Arch Ophthalmol. 2011;129:545-553.

79. Keates RH, McGowan KA. Clinical trial of flurbiprofen to maintain pupillary dilation during cataract surgery. Ann Ophthalmol. 1984;16:919-921.

80. Flach AJ, Dolan BJ, Irvine AR. Effectiveness of ketorolac tromethamine $0.5 \%$ ophthalmic solution for chronic aphakic and pseudophakic cystoid macular edema. Am J Ophthalmol. 1987; 103:479-486.

81. Flach AJ, Stegman RC, Graham J, Kruger LP. Prophylaxis of aphakic cystoid macular edema without corticosteroids. Ophthalmology. 1990;97:1253-1258.

82. Liesegang TJ. Viscoelastics. Int Ophthalmol Clin. 1993;33: 127-147.

83. Bainbridge JW, Mehat MS, Sundaram V, et al. Long-term effect of gene therapy on Leber's congenital amaurosis. $N$ Engl J Med. 2015;372:1887-1897.

84. Barnard AR, Groppe M, MacLaren RE. Gene therapy for choroideremia using an adeno-associated viral (AAV) vector. Cold Spring Harb Perspect Med. 2015;5:a017293.

85. Haller JA, Stalmans P, Benz MS, et al. Efficacy of intravitreal ocriplasmin for treatment of vitreomacular adhesion: subgroup analyses from two randomized trials. Ophthalmology. 2015;122: $117-122$.

86. AREDS. A randomized, placebo-controlled, clinical trial of highdose supplementation with vitamins $\mathrm{C}$ and $\mathrm{E}$, beta carotene, and 
zinc for age-related macular degeneration and vision loss: AREDS report no. 8. Arch Ophthalmol. 2001;119:1417-1436.

87. TAP Study Group. Photodynamic therapy of subfoveal choroidal neovascularization in age-related macular degeneration with verteporfin: one-year results of 2 randomized clinical trialsTAP report 1. Arch Ophthalmol. 1999;117:1329-1345.

88. Bressler SB, Qin H, Melia M, et al. Exploratory analysis of the effect of intravitreal ranibizumab or triamcinolone on worsening of diabetic retinopathy in a randomized clinical trial. JAMA Ophthalmol. 2013;131:1033-1040.

89. Scott AB. Botulinum toxin injection into extraocular muscles as an alternative to strabismus surgery. Ophthalmology. 1980;87: 1044-1049.

90. Frueh BR, Felt DP, Wojno TH, Musch DC. Treatment of blepharospasm with botulinum toxin. A preliminary report. Arch Ophthalmol. 1984;102:1464-1468.
91. Chia A, Chua WH, Wen L, Fong A, Goon YY, Tan D. Atropine for the treatment of childhood myopia: changes after stopping atropine $0.01 \%, 0.1 \%$, and $0.5 \%$. Am J Ophthalmol. 2014;157: 451-457.

92. Siatkowski RM, Cotter SA, Crockett RS, Miller JM, Novack GD, Zadnik K. Two-year multicenter, randomized, double-masked, placebo-controlled, parallel safety and efficacy study of $2 \%$ pirenzepine ophthalmic gel in children with myopia. J AAPOS. 2008; 12:332-339.

93. Tan DTH, Lam DS, Chua WH, Shu-Ping DF, Crockett RS, Group APS. One-year multicenter, double-masked, placebo-controlled, parallel safety and efficacy study of $2 \%$ pirenzepine ophthalmic gel in children with myopia. Ophthalmology. 2005;112:84-91.

94. Repka MX, Kraker RT, Holmes JM, et al. Atropine vs patching for treatment of moderate amblyopia: follow-up at 15 years of age of a randomized clinical trial. JAMA Ophthalmol. 2014;132:799-805. 